\title{
A Case of Occult Anaplastic Thyroid Cancer Presenting as Huge Renal Mass
}

\author{
Jong Hwan Lee ${ }^{1,2}\left(\mathbb{D}\right.$, Yunna Yang ${ }^{1,2}$, and Eun Jung Lee ${ }^{1,2} \mathbb{D}$ \\ ${ }^{1}$ Department of Otorhinolaryngology-Head and Neck Surgery, Jeonbuk National University School of Medicine, Jeonju; and \\ ${ }^{2}$ Research Institute of Clinical Medicine of Jeonbuk National University-Biomedical Research Institute of Jeonbuk National University \\ Hospital, Jeonju, Korea
}

\author{
거대 신장 종물로 발현된 잠재성 갑상선 역형성 암종 1 예 \\ 이종환 ${ }^{1,2} \cdot$ 양윤나 ${ }^{1,2}$ - 이은정 ${ }^{1,2}$ \\ 전북대학교 의과대학 이비인후-두경부외과학교실, ${ }^{1}$ 전북대학교 임상의학연구소-전북대학교병원 의생명연구원 ${ }^{2}$
}

\author{
Received July 12, 2020 \\ Revised August 20, 2020 \\ Accepted August 21, 2020 \\ Address for correspondence \\ Eun Jung Lee, MD, PhD \\ Department of Otorhinolaryngology- \\ Head and Neck Surgery, \\ Research Institute for Clinical \\ Medicine of Jeonbuk National \\ University-Biomedical Research \\ Institute of Jeonbuk National \\ University Hospital, \\ 20 Geonji-ro Deokjin-gu, \\ Jeonju 54907, Korea \\ Tel $+82-63-250-1980$ \\ Fax $+82-63-250-1986$ \\ E-mailimaima97@naver.com
}

Anaplastic thyroid cancers (ATC) are a rapid growing and highly lethal form of thyroid cancer. Distant metastases of ATC are detected in about half of patients. Clinically, it is very rare to metastasize to the kidney. The most common initial symptoms of ATC are a palpable neck mass and accompanying compression symptoms of the upper aerodigestive tract. A 68-yearold patient was referred with a huge renal mass, which was detected during the evaluation of abdominal pain. Left total nephrectomy was performed. Histologically, the kidney tumor was a metastatic anaplastic thyroid carcinoma. To our knowledge, it is the first case of occult ATC presenting as a huge renal mass.

Korean J Otorhinolaryngol-Head Neck Surg 2021;64(9):659-63

Keywords Kidney neoplasms; Neoplasm metastasis; Thyroid cancer, anaplastic.

\section{Introduction}

Occult primary tumors are defined as histologically confirmed metastatic malignancies, and the primary region is not recognized before treatment. ${ }^{1)}$ Occult thyroid carcinoma is common in the clinic; however, occult anaplastic thyroid cancer (ATC) is rare. ${ }^{2,3)}$ As far as our knowledge, there is none of reported case of occult ATC presenting as a renal metastatic lesion because almost all ATC patients present with a rapidly growing neck mass. However, distant metastases are found in early disease presentations in about half of patients. In partic-

This is an Open Access article distributed under the terms of the Creative Commons Attribution Non-Commercial License (https://creativecommons.org/licenses/by-nc/4.0) which permits unrestricted non-commercial use, distribution, and reproduction in any medium, provided the original work is properly cited. ular, some have metastases to the kidneys. ${ }^{4}$ Herein, we report the first case of occult anaplastic thyroid cancer which was initially considered to be a metastatic renal cell carcinoma (RCC).

\section{Case}

A 68-year-old patient was referred to the department of urology at our institution with a huge left renal mass which was detected incidentally on ultrasonography during the evaluation of abdominal pain. She had suffered from abdominal pain for 2 months before presentation. Physical examination presented a palpable mass in the left upper quadrant of the abdomen. No abnormal values were found in her blood chemistry with the exception of microscopic hematuria (26-30/HPF) 
on urine analysis. Computed tomography (CT) showed a 12$\mathrm{cm}$ exophytic cystic tumor in the left kidney, a 3.2-centimeter infiltrative mass in the paraumbilical portion of the liver, and small nodules in both basal lung fields (Fig. 1). Bone scan did not find any evidence of bone metastasis. Positron emission tomography (PET)-CT presented hypermetabolic nodules in the right thyroid gland, both lungs, liver, left kidney and left paraaortic and common iliac lymph nodes (Fig. 2A and B). These findings were suggestive of metastatic RCC. Sono-guided percutaneous needle biopsy of the hepatic mass was done, but no cancer component was revealed from the biopsy. In addition, the biopsy result was indicative of thyroid tissue showing a follicular structure containing colloid-like material, which was positive in immunohistochemistry stain with thyroglobulin (TG) and thyroid transcription factor-1 (TTF-1). Although our pathologist recommended a repeat bi- opsy, we considered that the mass could be a kind of RCC. We subsequently performed left total nephrectomy not only for the palliation of uncontrolled severe abdominal pain but also with the aim to administer adjuvant therapy. In addition, cytoreductive nephrectomy for metastatic RCC is known to improve median survival. ${ }^{5)}$ However, the final histopathologic result demonstrated that the renal mass was from ATC (Fig. 3). Microscopically, it presented a papillary and follicular proliferation with colloid like material in the intra-follicular space. The strongly positive immunohistochemical staining with TG and TTF-1 verified the origin from the thyroid gland and the diagnosis of ATC metastasising to kidney. Consequently, thyroid ultrasonography and fine needle aspiration cytology was done. Sub-centimeter sized ill-defined hypoechoic nodules with calcification were noted on right side of the thyroid gland diagnosed as nodular hyperplasia of the thyroid (Fig.
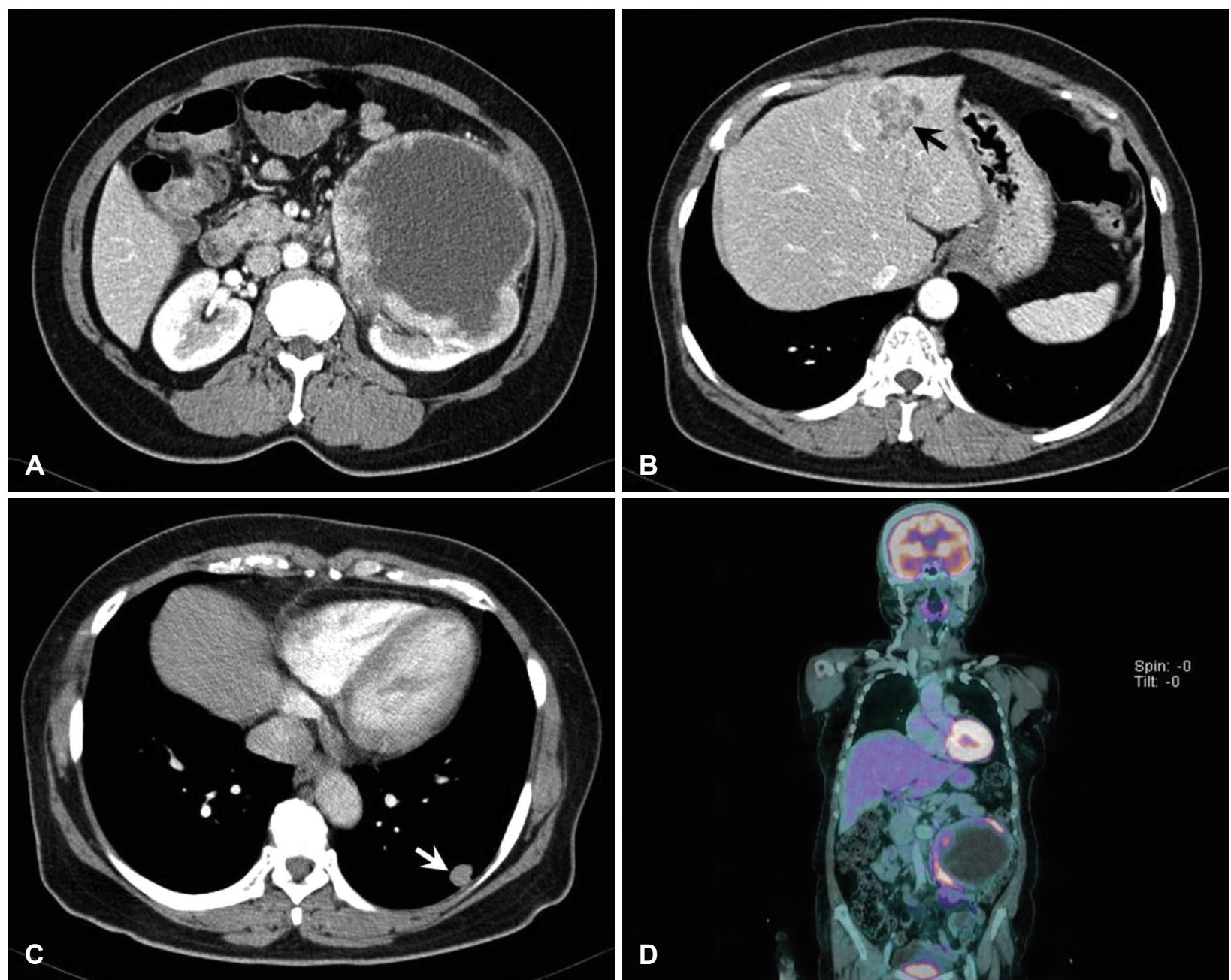

Fig. 1. Contrast-enhanced CT images showing a 12-cm exophytic cystic mass in the left kidney with intensely enhanced solid portion (A), a 3.2-cm infiltrative mass in the paraumbilical portion of the liver (arrow) (B), and small enhanced nodules in both basal lung fields (arrow) (C). PET-CT revealed hypermetabolic nodules in the right thyroid gland, both lungs, liver, left kidney and left paraaortic and common iliac lymph nodes (D). 

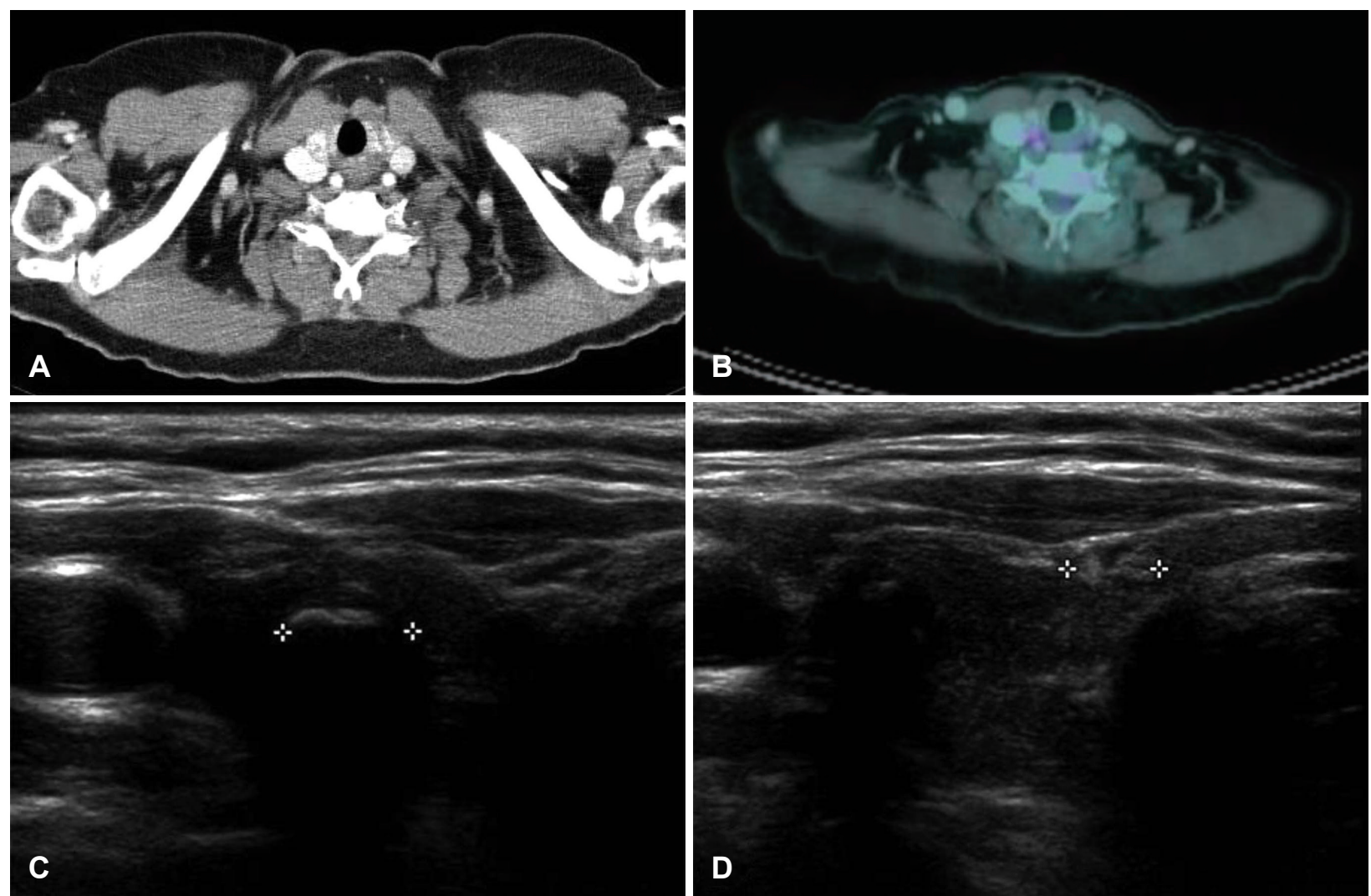

Fig. 2. Examinations to confirm thyroid origin. Contrast-enhanced CT images showing thyroid nodules with microcalcification in the right thyroid gland (A). PET-CT revealed hypermetabolic nodules in the right thyroid gland (B). Thyroid ultrasonography showing $(\mathrm{C}) 0.633 \mathrm{~cm}$ sized ill-defined hypoechoic nodule with calcification noted on right thyroid gland diagnosed as nodular hyperplasia on fine needle aspiration cytology and (D) $0.477 \mathrm{~cm}$ sized well-defined mixed echoic nodule with calcification noted on right thyroid gland.

$2 \mathrm{C}$ and D). After the operation, the patient was supposed to receive systemic chemotherapy or target therapy according to the biopsy result, but only supportive care was given due to her poor general condition and refusal of treatment. The patient showed an aggressive course despite appropriate supportive treatment. In spite of every effort of supportive care, the patient developed pulmonary thromboembolism with severe airway compromise due to multiple hematogenous lung metastasis and expired from respiratory distress 8 weeks after the surgery.

\section{Discussion}

The initial symptom of ATC is an extremely rapidly growing neck mass, occurring in about $85 \%$ of patients with ATC. The ATC may cause tenderness and neck pain, and compression (or direct invasion) of the airway and digestive organs, causing dyspnea (about $35 \%$ of patients), swallowing difficulty $(30 \%)$, hoarseness $(25 \%)$, and cough (and sometimes hemoptysis, 25\%). Less common clinical manifestation are chest discomfort, headache, bone pain, mental confusion, or abdominal pain from metastases. ${ }^{6}$

Distant metastases are recognized at initial evaluation in $15 \%$ to $50 \%$ of patients. ${ }^{4,-9)}$ ATC usually metastasizes to distant organs via the bloodstream. The lung is the most common site of metastasis, up to $90 \%$ of patients with distant disease are involved. ${ }^{899}$ The second most common regions of distant disease are the bone and brain, and some patients have metastatic legions to the skin, kidneys, liver, pancreas, heart and adrenal glands. ${ }^{8-11)}$ Metastasis to the kidney caused by ATC is found in $16 \%$ of patients at postmortem autopsy. ${ }^{12)}$ However, only one case has been reported with renal metastasis of ATC. ${ }^{8)}$

Occult ATC is very rare. Aldinger, et al. ${ }^{13)}$ reported ATC in a patient with neck free from disease. In this case, papillaryfollicular carcinoma was found in the thyroid gland. After 8 years, metastatic ATC was present at postmortem examination. Takashima, et al. ${ }^{3)}$ reported that ATC with metastatic lymph node mimicked a parathyroid tumor.

ATCs are severely aggressive disease, with a disease-specific mortality approaching $100 \%$. In a review of published 

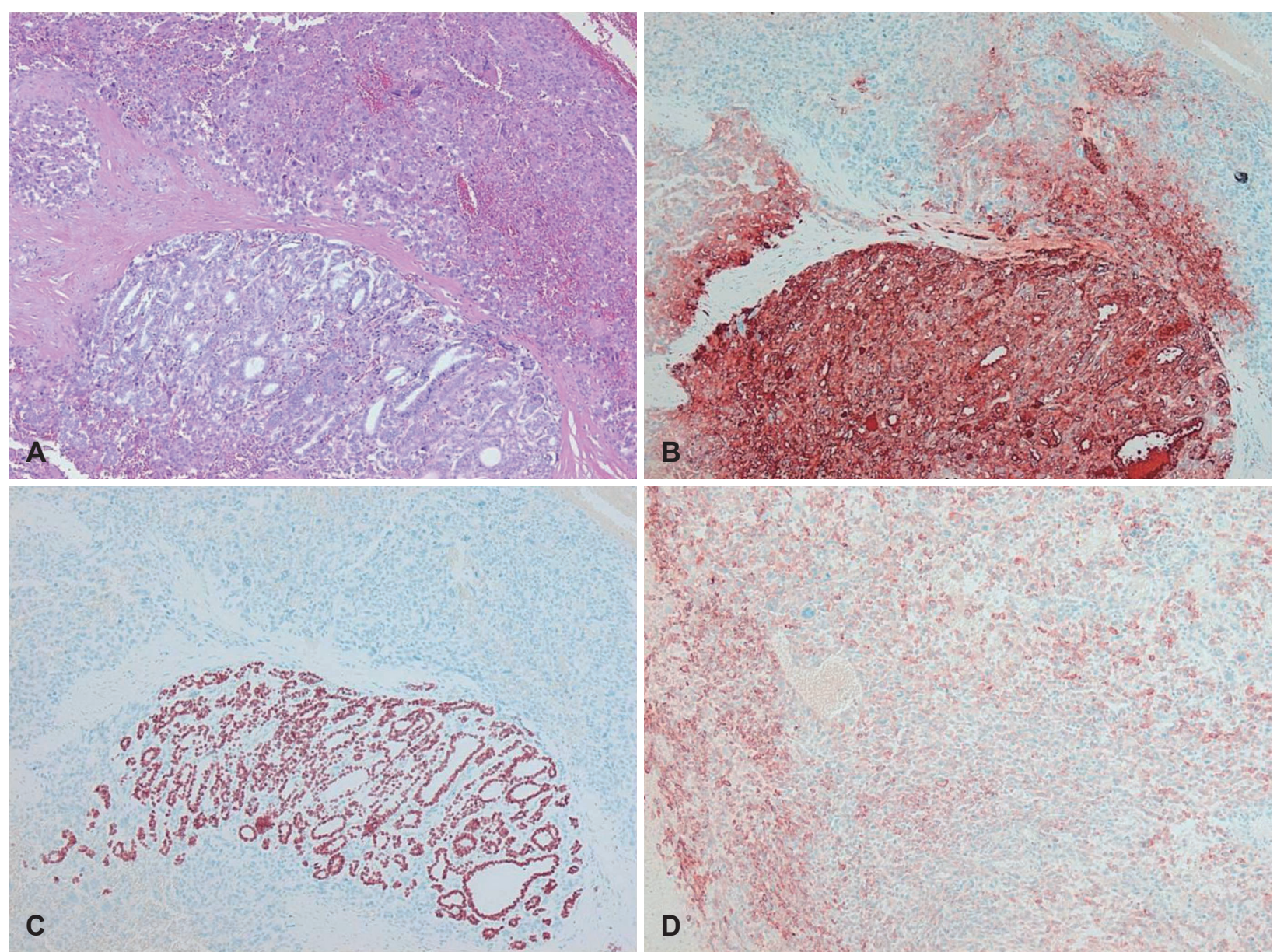

Fig. 3. Histopathological findings. Round-to-oval shaped follicle lined with follicular cells, however, colloidal material not seen (lower part of image), and marked degree of pleomorphism pattern (upper part of image) (hematoxylin and eosin, $\times 100)(A)$. Strong cytoplasmic expression of TG on round-to-oval shaped follicle (lower part of image) $(T G, \times 100)(B)$. Strong nuclear expression of TTF-1 on round-tooval shaped follicle (lower part of image) $(T T F-1, \times 100)(C)$. Moderate cytoplasmic expression of epithelial membrane antigen on tumor cells (epithelial membrane antigen, $\times 100)(D)$. TG: Thyroglobulin, TTF-1: thyroid transcription factor-1.

case series (1771 patients treated between 1949 and 2007), the median survival was 5 months, and the 1-year survival was $20 \%{ }^{14)}$ The median survival in patients with ATC with distant metastases at the time of diagnosis was 4.2 months, compared with 6 months in those without metastases. ${ }^{15)}$ In patients with advanced tumor, palliation of symptoms is a high priority.

In our patient, the authors considered the disease to be an advanced RCC with multiple metastases at presentation. Initially, we had planned neoadjuvant targeted therapy because the patient had good performance status at that time. Subsequently, we performed sono-guided percutaneous needle biopsy of the hepatic lesion to clarify the cell type of the RCC. However, unfortunately no cancer component was revealed by the biopsy, and, in addition, the biopsy result was indicative of thyroid tissue showing a follicular structure containing colloid-like material, which was positive in immunohistochemical staining with TTF-1 and TG. Although our patholo- gist recommended repeat biopsy, the authors still considered that the mass could be a kind of RCC at that time. In addition, cytoreductive nephrectomy was inevitabllly decided for palliative treatment due to severe uncontrolled abdominal pain. This case shows that repeated biopsies should be carried out before cytoreductive nephrectomy for proper management whenever the preoperative biopsy result is not appropriate to confirm a renal cancer. Furthermore, we should remember that ATC can metastasize to the kidney, and the neck may be free from disease.

This study was reviewed and approved by Institutional Review Board: CUH 2020-07-010.

\section{Acknowledgments}

None.

\section{Author Contribution}

Visualization: Yunna Yang. Writing_-original draft: Jong Hwan 
Lee. Writing—review \& editing: Eun Jung Lee.

\section{ORCIDs}

Eun Jung Lee https://orcid.org/0000-0001-6958-0312

Jong Hwan Lee

\section{REFERENCES}

1) Greco FA, Hainsworth JD. Cancer of unknown primary site. In: DeVita VT, Lawrence TS, Rosenberg SA, editors. DeVita, Hellman, and Rosenberg's Cancer: Principles \& Practice of Oncology. 8th ed. Philadelphia: Lippincott Williams \& Wilkins; 2008. p.2363-87.

2) Deutschmann M, Khalil M, Bhayana S, Chandarana S. Occult multifocal papillary thyroid microcarcinoma presenting as a supraclavicular mass containing anaplastic thyroid carcinoma. JAMA Otolaryngol Head Neck Surg 2013;139(4):415-8.

3) Takashima S, Morimoto S, Ikezoe J, Kokado Y, Kozuka T. Occult anaplastic thyroid carcinoma associated with marked hypercalcemia. J Clin Ultrasound 1990;18(5):438-41.

4) McIver B, Hay ID, Giuffrida DF, Dvorak CE, Grant CS, Thompson $\mathrm{GB}$, et al. Anaplastic thyroid carcinoma: A 50-year experience at a single institution. Surgery 2001;130(6):1028-34.

5) Conti SL, Thomas IC, Hagedorn JC, Chung BI, Chertow GM, Wagner TH, et al. Utilization of cytoreductive nephrectomy and patient survival in the targeted therapy era. Int J Cancer 2014; 134(9):2245-52.

6) Lip GY, Jaap AJ, McCruden DC. A presentation of anaplastic carcinoma of the thyroid with symptomatic intra-abdominal

metastases. Br J Clin Pract 1992;46(2):143-4

7) Nel CJ, van Heerden JA, Goellner JR, Gharib H, McConahey WM, Taylor WF, et al. Anaplastic carcinoma of the thyroid: A clinicopathologic study of 82 cases. Mayo Clin Proc 1985;60(1):51-8.

8) Carcangiu ML, Steeper T, Zampi G, Rosai J. Anaplastic thyroid carcinoma. A study of 70 cases. Am J Clin Pathol 1985;83(2):13558.

9) Venkatesh YS, Ordonez NG, Schultz PN, Hickey RC, Goepfert H, Samaan NA. Anaplastic carcinoma of the thyroid. A clinicopathologic study of 121 cases. Cancer 1990;66(2):321-30.

10) Tan RK, Finley RK 3rd, Driscoll D, Bakamjian V, Hicks WL Jr, Shedd DP. Anaplastic carcinoma of the thyroid: A 24-year experience. Head Neck 1995;17(1):41-7; discussion 47-8.

11) Hadar T, Mor C, Shvero J, Levy R, Segal K. Anaplastic carcinoma of the thyroid. Eur J Surg Oncol 1993;19(6):511-6.

12) Heitz P, Moser H, Staub JJ. Thyroid cancer: A study of 573 thyroid tumors and 161 autopsy cases observed over a thirty-year period. Cancer 1976;37(5):2329-37.

13) Aldinger KA, Samaan NA, Ibanez M, Hill CS Jr. Anaplastic carcinoma of the thyroid: A review of 84 cases of spindle and giant cell carcinoma of the thyroid. Cancer 1978;41(6):2267-75.

14) Smallridge RC, Copland JA. Anaplastic thyroid carcinoma: Pathogenesis and emerging therapies. Clin Oncol (R Coll Radiol) 2010;22(6):486-97.

15) Ito $K$, Hanamura $T$, Murayama $K$, Okada $T$, Watanabe $T$, Harada $\mathrm{M}$, et al. Multimodality therapeutic outcomes in anaplastic thyroid carcinoma: Improved survival in subgroups of patients with localized primary tumors. Head Neck 2012;34(2):230-7. 